\title{
FORMAÇÃO DOCENTE EM DEBATE NA PÓS-GRADUAÇÃO STRICTO SENSU EM EDUCAÇÃO FÍSICA
}

\author{
Amanda Pires Chaves \\ Universidade Estadual de Londrina - UEL. Pós-Graduação em Educação, Londrina - PR. Financiamento: CAPES. E-mail: \\ amanda.pireschaves@gmail.com
}

\section{RESUMO}

O artigo analisa os resultados parciais de uma pesquisa referente à formação docente na PósGraduação Stricto Sensu, na qual um dos objetivos foi conhecer ações e propostas relativas à formação docente em um Curso de Pós-Graduação Stricto Sensu em Educação Física numa universidade pública. Trata-se de um estudo qualitativo, de caráter exploratório-descritivo, que consultou, por meio de entrevista semiestruturada, coordenadores de um Programa de PósGraduação Stricto Sensu em Educação Física. Entre outros, autores como Soares e Cunha (2010); Bolzan e Isaia (2010); Goergen (2006) e, Pimenta e Anastasiou (2002) fundamentam as análises. Como resultado preliminar, consideramos que o Programa de Pós-Graduação Stricto Sensu investigado, tem buscado uma formação docente de qualidade, tentando aliar em suas propostas e ações o equilíbrio entre a formação para o ensino e a formação para a pesquisa, articulando a relação entre ensino e pesquisa nos processos de formação de seus alunos.

Palavras-chave: Formação de professores, Ensino Superior, Docência Universitária, Stricto Sensu, Pós-Graduação.

\section{TEACHER TRAINING IN DISCUSSION ON GRADUATE STRICTO SENSU STUDIES IN PHYSICAL EDUCATION}

\begin{abstract}
This paper analyzes the partial results of a survey regarding teacher training in post-graduate studies, in which one of the goals was to learn actions and proposals on teacher training course at a stricto sensu graduate programs in physical education at a public university. This is a qualitative study, exploratory-descriptive, who consulted through semi-structured interviews, coordinators of a program of post-graduate studies in Physical Education. Among others, authors like Smith and Cunha (2010); Bolzan and Isaia (2010); Goergen (2006) and Pepper and Anastasiou (2002) underlie the analyzes. As a preliminary result, believes that the program of post-graduate studies investigated, has been seeking a quality teacher training, trying to combine their proposals and actions on a balance between training for teaching and training for research, articulating the relationship between teaching and research in the processes of formation of their students.
\end{abstract}

Keywords: Teacher education, Higher Education, University Teaching, Stricto Sensu, PostGraduate.

\section{INTRODUÇÃO}


Este trabalho apresenta alguns resultados parciais de uma pesquisa realizada em uma Universidade pública que teve como objetivos: conhecer ações e propostas relativas à formação docente em um Programa de Pós-Graduação Stricto Sensu em Educação Física; compreender o papel das disciplinas de núcleo comum deste Programa, no desenvolvimento da formação docente universitária; e aprofundar estudos a respeito do referencial teórico sobre formação docente universitária e Pós-Graduação Stricto Sensu no Brasil. Este texto analisa especificamente percepções dos coordenadores do Programa a respeito da formação docente universitária que está sendo desenvolvida no Curso, realizando um diálogo reflexivo entre as informações encontradas e a literatura existente.

\section{METODOLOGIA}

Este estudo caracteriza-se como um estudo qualitativo, de caráter exploratóriodescritivo, visto que com intuito de familiarizar-se com o fenômeno que investigado, a pesquisa pretendeu "proporcionar maior familiaridade com o problema, com vistas a torná-lo mais explícito ou a construir hipóteses", aprimorando as ideias ou descobrindo intuições (GIL, 2010, p. 27).

Como instrumento de pesquisa, utilizamos a entrevista semiestruturada com os dois coordenadores do Programa como meio para acessar maiores informações que permitissem analisar $o$ processo de desenvolvimento da formação docente realizada na realidade estudada. Visto que este Programa de Pós-Graduação Stricto Sensu é associado, portanto fazem parte do mesmo Programa duas Universidades públicas, existem dois coordenadores responsáveis pelo mesmo, sendo um responsável por cada instituição.

\section{DISCUSSÃO}

Refletir sobre a docência universitária e a formação pedagógica requer a busca de suas raízes históricas e legais que as permeiam para melhor compreendê-las.

De acordo com Veiga (2006, p.85), o termo docência deriva do latim - docere "que significa ensinar, instruir, mostrar, indicar, dar e entender", e, ainda, segundo a autora (2006) apoiada em Araújo (2004), na língua portuguesa o primeiro registro datado desta palavra foi em 1916, o que permite afirmar que a apropriação do termo é algo novo nos processos de discursos no âmbito da educação.

Segundo Cunha (2005) o valor significativo dado ao conhecimento técnico no processo de formação e na carreira docente, possui, além das raízes históricas no latim, influências da ciência moderna, regida pela racionalidade técnica. 
Assim, espera-se e atribui-se até hoje ao professor o papel de transmissor de conhecimentos, alicerçado somente nos saberes do campo científico e técnico de sua área, como se a carreira do docente universitário se estabelecesse apenas na dimensão científica. Partindo dessa premissa, desde o século $X X$, as políticas públicas vêm instituindo-se em ligação entre o Estado, a universidade e a sociedade (CUNHA, 2005), buscando atender as necessidades encontradas nestes meios.

Há uma vasta demanda de leis que regem as políticas públicas relacionadas à formação para docência no ensino superior, deste modo daremos atenção especial a algumas delas, consideradas essenciais.

De acordo com a Lei de Diretrizes e Bases da Educação Nacional (LDB), no parecer 9.394/96, artigo 66, a “preparação do professor para o ensino superior far-se-á em nível de pós-graduação, prioritariamente em programas de mestrado e doutorado" (BRASIL, 1996, P.23). Contudo, esta lei deixa lacunas, uma vez que neste mesmo parecer, no artigo 52, inciso II, estabelece como percentual mínimo cerca de 33\% de mestres e doutores no quadro funcional das instituições de ensino superior, deste modo, não é uma condição para o ingresso e permanência na docência superior a preparação referida na lei acima.
Esta mesma Lei 9394/96, no artigo 13, estabelece as seguintes responsabilidades aos professores:

- participar da elaboração do projeto pedagógico;

- elaborar e cumprir o plano de trabalho;

- zelar pela aprendizagem dos alunos;

- estabelecer estratégias de recuperação para os alunos de menor rendimento;

- ministrar os dias letivos e horas-aula estabelecidos;

- participar integralmente dos períodos dedicados ao planejamento, à avaliação e ao desenvolvimento profissional.

Dado o exposto, não há dúvida de que o processo de formação e preparação para a docência engloba, além do conhecimento científico, o conhecimento pedagógico, não claramente explicitado nas leis acima.

Em contrapartida, os Planos Nacionais de Pós-Graduação (PNPGs), de responsabilidade da Coordenação de Aperfeiçoamento de Pessoal de Nível Superior (Capes), contemplam como consequência natural da formação do pesquisador a formação do docente universitário, conceito este vinculado ao pensamento de indissociabilidade entre ensino e pesquisa. Entretanto, segundo Soares e Cunha (2010, p. 582) "[...] o estatuto epistemológico que sustenta as práticas de ensinar e aprender na universidade não 
confirma os elos automáticos entre ensino e pesquisa". E, também, de acordo com Veiga (2006, p. 88) “[...] os Programas de Pósgraduação se voltam para a formação de pesquisadores em seus campos específicos e sem exigência quanto à formação pedagógica de professores".

A atenção voltada prioritariamente à formação do pesquisador, no caso dos professores universitários, fica evidente quando o professor é avaliado e prestigiado como um professor de sucesso por seu grau de produtividade e a vertente da emancipação é deixada de lado em sua profissão (CUNHA, 2005).

No entanto, também como referencial, o Plano Nacional de Graduação: um projeto em construção (PNG), estruturado em torno de princípios, fundamentos e diretrizes, exige a construção de um novo perfil docente, pois suas ideias centrais requer que o professor tenha:

- formação científica na área do conhecimento;

- pós-graduação stricto sensu preferentemente, no nível de doutorado;

- domínio do complexo processo histórico de constituição de sua área;

- ampla e crítica compreensão dos métodos que produziram $\mathrm{o}$ conhecimento acumulado;

- competência pedagógica (FORGRAD, 2004).
Sendo assim, o plano evita o isolamento científico do pesquisador, exige e dá ênfase ao processo de formação pedagógica do professor universitário. E, ainda, o documento salienta que a titulação deve ser considerada como condição necessária, porém não é suficiente, para o desempenho adequado da docência, ou seja, além de portar o diploma que confere ao professor o saber do campo científico, o professor precisa dominar conhecimentos pedagógicos.

Por tudo isso, as políticas públicas relacionadas à formação para a docência universitária ainda apresentam muitas lacunas, tornando-se um processo obscuro, sem um caminho que possa ser trilhado, dificultando a construção de uma formação com eficácia. No entanto, sabemos que formar professores universitários requer possibilitar o desenvolvimento de competências científico-pedagógicas que os prepare para enfrentar os desafios atuais da sua profissão.

\section{RESULTADOS}

Um dos grandes desafios da docência universitária na atualidade está em aliar ensino e pesquisa (CUNHA, 2005). De imediato, é possível verificar novas mudanças no contexto universitário que exigem do professor novas capacidades para conciliar ensino e pesquisa; sendo assim, este 
principal desafio acaba suscitando outras dificuldades para profissão.

Em decorrência da exigência da produtividade do professor, exacerba-se o individualismo. Segundo Cunha (2005, p.88), a relação antes estabelecida entre professores e alunos no processo de produção está cada vez mais se estreitando, uma vez que "O docente é valorizado pelo que produz individualmente ou com seus orientandos [...] Em muitas ocasiões, o que se estabelece é apenas a relação do professor com seus próprios livros e/ou computador".

Sobre esta relação entre orientador e aluno nos Programas de Pós-Graduação Stricto Sensu, um dos coordenadores enfatizou que esta relação é de extrema importância para a formação do futuro docente universitário, uma vez que possibilita uma troca de saberes; contudo, ressaltou que esta importância tem como ponto positivo o envolvimento do aluno em atividades especificamente científicas, deixando de lado a relevância da troca de saberes entre professor e o aluno para a formação docente, ou seja, formação para o ensino propriamente dito.

Coordenador A - “O
orientador tem o papel
importante em estar
orientando os passos da
redação acadêmico-
científica, que é um ponto
muito importante para o
professor, a questão da
linguagem, tanto a

linguagem científica quanto a linguagem em nível de precisão de informação".

Além da produtividade de pesquisas e da exacerbação do individualismo gerado pela função do professor pesquisador, o professor universitário é chamado a ser docente por meio de uma vivência colaborativa, ensinando e aprendendo. Contudo, Bolzan e Isaia (2010, p.23) afirmam que "há uma evidente ausência de um saber pedagógico capaz de promover atividades de compartilhamento e colaboratividade no processo de ensino e de aprendizagem". Segundo Soares e Cunha (2010, p.590), isto ocorre devido ao equívoco ainda existente no meio universitário de "pensar que os saberes inerentes à pesquisa se transferem automaticamente para o ensino". E, também, de acordo com as autoras (2010, p. 590), “é imprescindível à incorporação dos saberes do campo pedagógico para fazer a necessária mediação entre ensino e pesquisa".

Quanto à incorporação dos saberes pedagógicos, ligados ao ensino, e dos específicos, ligados à pesquisa e aos conhecimentos científicos, interrogamos os coordenadores sobre as disciplinas existentes no Programa de Pós-Graduação Stricto Sensu que estão inseridos e suas contribuições para a formação docente, e a difícil associação e equilíbrio entre disciplinas mais específicas e disciplinas mais pedagógicas. Como 
respostas, obtivemos que no Programa existem disciplinas denominadas de núcleo comum, que são obrigatórias e possuem maior constância, e que atendem tanto a formação do docente, como a do pesquisador. E, também as disciplinas chamadas de tópicos especiais, que são esporádicas e mais específicas, mas não deixam de formar tanto o docente como o pesquisador, como os coordenadores indicaram nos relatos.

Coordenador A - "Na verdade existem várias vertentes, por exemplo, as disciplinas de núcleo comum elas tem uma consistência, uma abrangência maior no que tange ao nível de conhecimento

generalizado, mas nós não podemos desprezar a capacidade das disciplinas específicas em auxiliar a formação do docente que vai acabar atuando em disciplinas específicas, então as duas são importantes. O ideal é que o individuo que está em formação, em fase de formação em nível de mestrado e doutorado, tenha oportunidade de usufruir das duas condições, tanto das disciplinas eletivas, específicas, quanto aquelas de núcleo comum".

Coordenador B -
"Especialmente as de
núcleo comum contribuem
para a formação docente,

mas eventualmente nós temos outras que a gente chama de tópicos especiais, que também tem esse olhar para atuação no campo do ensino, mas essas de tópicos especiais são disciplinas que são esporádicas, então não dá muito para contar pra que essa formação ocorra porque não é garantida".

Quando indagados sobre o alcance de uma das finalidades da Pós-Graduação proposta pela LDB, no caso a formação de professores para o ensino superior, os dois coordenadores foram unânimes em suas respostas. Eles acreditam que esta finalidade tem sido alcançada no Programa de PósGraduação Stricto Sensu em que estão inseridos, e ainda apontaram como consequência positiva a atuação de alunos egressos como docentes do ensino superior.

Coordenador A - "Eu acredito que sim, e acredito com conviç̧ão, uma vez que vários daqueles estudantes que passaram pelo nosso programa hoje já vem atuando em diferentes instituições de nível superior, tanto públicas, quanto privadas".

Coordenador B - "Olha eu entendo que sim, porque nós temos um registro de muitos dos nossos egressos atuando em universidades, em diversas universidades e faculdades". 
Não obstante, compreendemos que um grande desafio posto ainda aos professores universitários na atualidade está especialmente ligado à árdua tarefa de aliar conhecimentos pedagógicos, científicos e específicos, ou seja, interligar ensino e pesquisa em sua profissão. Entretanto, consideramos a priori que as lacunas existentes nas políticas públicas vêm acentuando e dificultando a formação do docente universitário.

\section{CONCLUSÃO}

Foi possível perceber que um dos grandes desafios da docência universitária está em aliar ensino e pesquisa, visto que, além do professor ser pesquisador, o professor deve exercer sua docência. Outro aspecto a considerar é que talvez seja pelo equívoco de se pensar que os saberes da pesquisa se transferem automaticamente para o ensino ou pelo fato de as políticas públicas não serem tão claras quanto ao processo de formação do docente universitário, o campo pedagógico está sendo deixado de lado.

Por outro lado, pudemos verificar por meio da análise parcial dos dados que o Programa de Pós-Graduação Stricto Sensu investigado, vem buscando uma formação docente de qualidade, tentando aliar em suas propostas e ações o equilíbrio entre a formação para o ensino e a formação para a pesquisa, tendo como objetivo uma relação articulada entre ensino e pesquisa nos processos de formação de seus alunos, mesmo sendo pressionado por políticas públicas e avaliações de caráter meramente produtivo, que induzem a formação do pesquisador e dificultam a formação para a docência em si.

\section{REFERÊNCIAS}

ARAÚJO, José Carlos Souza. Docência e ética: da dimensão interativa entre sujeitos ao envolvimento sócio institucional. In: ROMANOWISKI, Joana Paulin; MARTINS, Pura Lúcia Oliver; JUNQUEIRA, Sérgio Rogério Azevedo (Orgs.). Conhecimento local e conhecimento universal: práticas sociais, aulas, saberes e políticas. Curitiba: Champagnat, 2004.

BOLZAN, Doris Pires Vargas; ISAIA, Silvia Maria de Aguiar. Pedagogia universitária e aprendizagem docente: relações e novos sentidos da professoralidade. Revista Diálogo Educacional, Curitiba, v.10, n.29, p.13-26, jan./abr. 2010.

BRASIL, CONSELHO FEDERAL DE EDUCAÇÃO. Parecer CFE n. 977/65. Revista Brasileira de Educação, n.30, 2005.

BRASIL, MINISTÉRIO DA EDUCAÇÃO E CULTURA. Lei n. 9394/96, de 20 de dezembro de 1996. Estabelece as Diretrizes e Bases da Educação Nacional. Brasília: MEC, 1996. Disponível em: $<$ http://portal.mec.gov.br/arquivos/pdf/ldb.p df>. Acesso em: jun. 2013.

CUNHA, Maria Isabel da. et al. As políticas públicas e docência na universidade. In: 
CUNHA, Maria Isabel da (org.) Formatos avaliativos e concepção de docência. Campinas: Autores Associados, 2005, p.6991.

DONATO, M. E. Inovações na formação de docentes universitários: a experiência das ciências veterinárias. In: CUNHA, Maria Isabel. Reflexões e práticas em pedagogia universitária. Campinas: Papirus, 2007. p. 125-144.

FORGRAD, Plano Nacional de Graduação: um processo em construção. In: FORGRAD. Resgatando espaços e construindo ideias. 3a ed. ampl. Uberlândia: Edufu, 2004.

GIL, Antônio Carlos. Como elaborar projetos de pesquisa. 5. ed. São Paulo: Atlas, 2010.

PIMENTA, S. G.; ANASTASIOU, L. das G. C. Docência no ensino superior. São Paulo: Cortez, 2002.

SOARES, Sandra Regina; CUNHA, Maria Isabel da. Programas de pós-graduação em educação: lugar de formação da docência universitária? Revista Brasileira de PósGraduação, Brasília, v.7, n.14, dez.2010, p.577-604.

VEIGA, Ilma Passos Alencastro. Docência universitária na educação superior. In: RISTOFF, Dilvo; SEVEGNANI, Palmira. Docência na educação superior. Brasília: Instituto Nacional de Estudos e Pesquisas Educacionais Anísio Teixeira, 2006, p.85-96.

SAVIANI, D. Educação: do senso comum à consciência filosófica. 12. ed. Campinas: Autores Associados, 1996.

Recebido para publicação em 20/07/2014

Revisado em 02/09/2014

Aceito em 22/09/2014 